Erratum

\title{
Erratum to "Experimental Analyses of the Major Parameters Affecting the Intensity of Outbursts of Coal and Gas"
}

\author{
W. Nie, ${ }^{1}$ S. J. Peng, ${ }^{1}$ J. Xu, ${ }^{1}$ L. R. Liu, ${ }^{1}$ G. Wang, ${ }^{2}$ and J. B. Geng ${ }^{1}$ \\ ${ }^{1}$ State Key Laboratory of Coal Mine Disaster Dynamics and Control, Chongqing University, Chongqing 400044, China \\ ${ }^{2}$ Key Laboratory of Ministry of Education for Mine Disaster Prevention and Control, Shandong University of Science \\ and Technology, Qingdao 266510, China \\ Correspondence should be addressed to W. Nie; niewen1026@gmail.com \\ Received 11 November 2014; Accepted 25 November 2014; Published 8 December 2014 \\ Copyright $\odot 2014$ W. Nie et al. This is an open access article distributed under the Creative Commons Attribution License, which \\ permits unrestricted use, distribution, and reproduction in any medium, provided the original work is properly cited.
}

Here, we correct the errors made in Table 3 and equation (5) in the paper titled "Experimental Analyses of the Major Parameters Affecting the Intensity of Outbursts of Coal and Gas." The purpose of this paper is to correct both the data input and the mathematical errors in Table 3 and equation (5).

The data input (Gas pressure (Mpa)) in Column 5, Table 3 , should be as in the table mentioned in this paper.

The coefficients in equation (5) should be changed to

$$
\begin{array}{r}
\mathrm{RI}=-1.5874 x_{1}+2.866 x_{2}-0.3791 x_{3}+19.567 x_{4}, \\
x_{4} \geq 0.72 .
\end{array}
$$


TABLE 3: Coupled factors and relative intensity of outburst in coal and gas.

\begin{tabular}{|c|c|c|c|c|c|}
\hline \multicolumn{5}{|c|}{ Factors } & \multirow{2}{*}{$\begin{array}{l}\text { Results of experiments } \\
\text { Relative intensity (\%) }\end{array}$} \\
\hline Test number & Moisture (\%) & Geostress (MPa) & Porosity (\%) & Gas pressure $(\mathrm{MPa})$ & \\
\hline 1 & 0 & 3.4 & 3.1 & 1.5 & 39.2 \\
\hline 2 & 3.6 & 1.9 & 3.3 & 0.75 & 10.9 \\
\hline 3 & 2.6 & 1.8 & 2.3 & 1 & 24.1 \\
\hline 4 & 2.4 & 2 & 3.6 & 0.75 & 16.5 \\
\hline 5 & 3.6 & 1.3 & 2.4 & 1.5 & 17.2 \\
\hline 6 & 2.8 & 3.3 & 0.5 & 0.75 & 23.57 \\
\hline 7 & 3.4 & 3.4 & 1.7 & 1 & 19.2 \\
\hline 8 & 2.6 & 4 & 3.3 & 1 & 24.5 \\
\hline 9 & 4 & 4 & 3.1 & 1 & 23.8 \\
\hline 10 & 4.8 & 3 & 2.8 & 0.75 & 19.23 \\
\hline 11 & 3.6 & 4 & 3.3 & 1 & 22.9 \\
\hline 12 & 8 & 3.8 & 2.2 & 0.5 & 0 \\
\hline 13 & 2.8 & 4 & 3.6 & 1.5 & 26 \\
\hline 14 & 7.2 & 1 & 3.6 & 1 & 5.87 \\
\hline 15 & 7.2 & 2.1 & 1.4 & 1 & 18.5 \\
\hline 16 & 0 & 0.6 & 0.6 & 0 & 0 \\
\hline
\end{tabular}

Remarks: moisture: level 1 (0-2.7), level 2 (2.7-5.4), and level 3 (5.4-8); geostress: level 1 (0-1.33), level 2 (1.33-2.66), and level 3 (2.66-4); porosity: level 1 (0$1.2),(1.2-2.4)$, and level 3 (2.4-3.6); gas pressure: level 1 (0-0.5), level 2 (0.5-1), and level $3(1-1.5)$. 


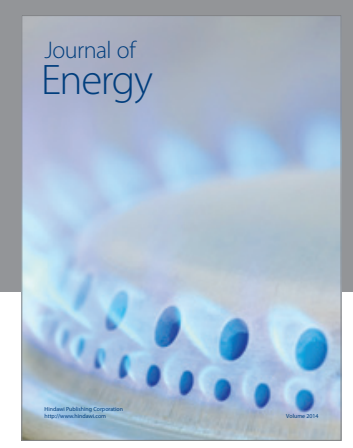

Journal of

Industrial Engineering
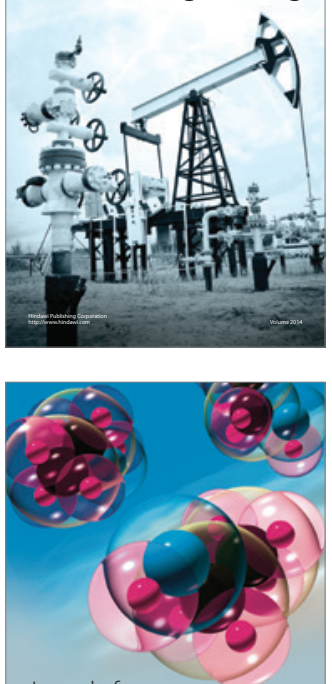

Fuels
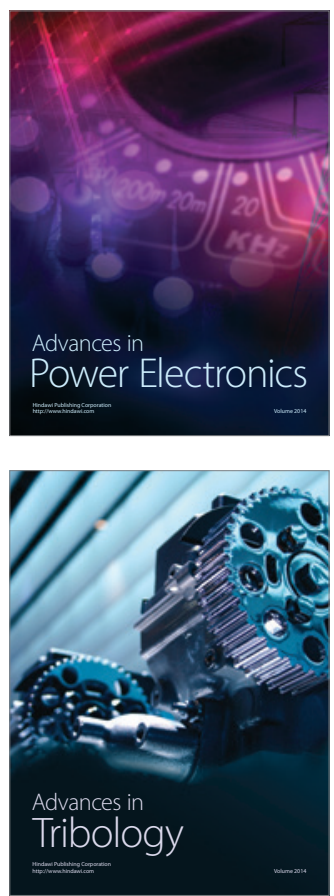

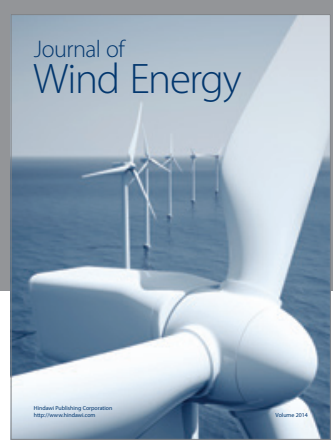

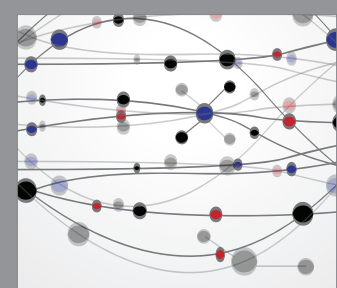

The Scientific World Journal

Submit your manuscripts at http://www.hindawi.com

Journal of

Structures
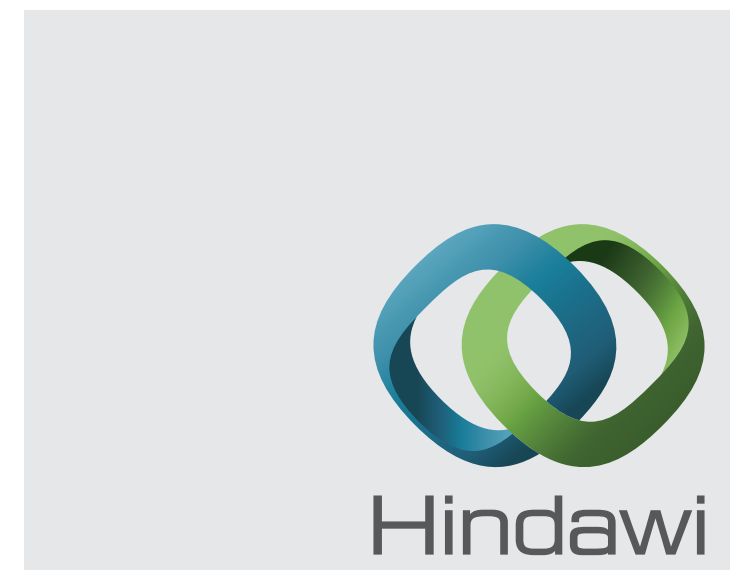

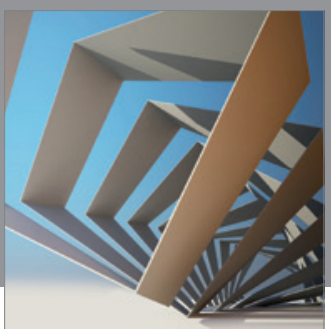

Rotating

Machinery
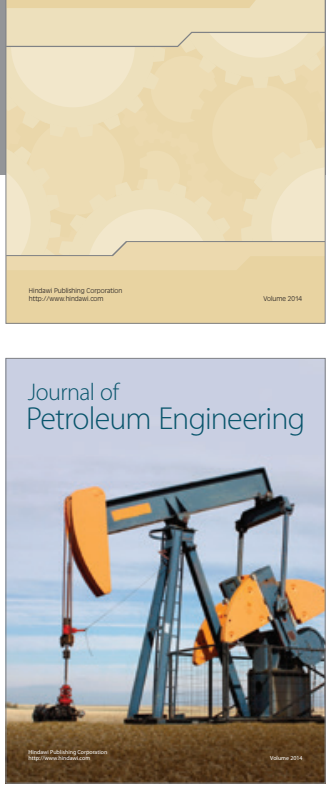

Journal of

Solar Energy
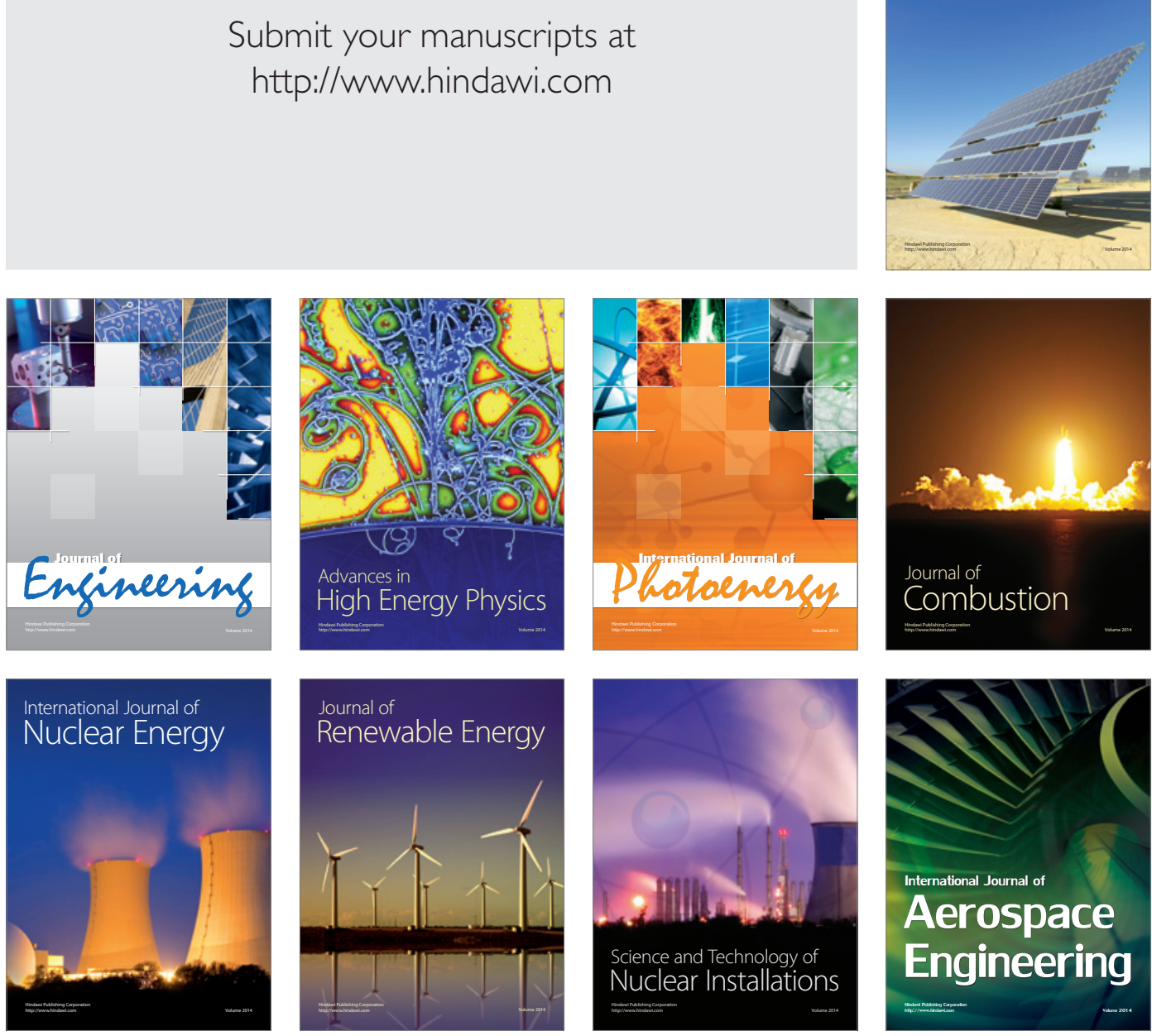